\title{
A Rare Case of Non-Syndromic Multiple Non-Ossifying Fibromas
}

Harsh Tantia*, Chithirai Selvam, Kalaichezhian Mariappan, Venkatraman Indiran, Prabakaran Maduraimuthu Department of Radiodiagnosis, Sree Balaji Medical College and Hospital, Chennai, Tamilnadu, India

Article History

Received: 03.09.2020

Accepted: 22.09 .2020

Published: 17.11.2020

Journal homepage:

https://www.easpublisher.com/easjirit

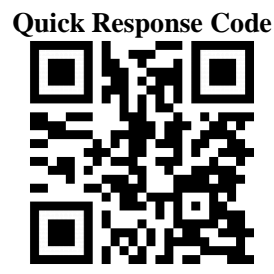

Abstract: Syndromic Multifocal non-ossifying fibromas have been reported in patients with the Jaffe-Campanacci syndrome and in patients with Type 1 neurofibromatosis[1-3]. Evans and park reported a rare case of three members of a family with the existence of multiple, symmetrical, non-ossifying fibromatosis without associated neurofibromatosis [5]. Here we report a rare case of non-syndromic multiple non-ossifying fibromas. A 23-year-old male complained of bowing deformity in the Right knee for 10 years. The deformity was insidious in onset, gradually progressive on nature, and made him sit with a wide base. Initially, the base was non-progressive with minimal distance between the two feet but now the distance has increased to the length of a brick. There was no history of pain, trauma, or difficulty to perform routine activities. On examination, Genu Valgum of Right knee was diagnosed and the disappearance of Deformity was noted during flexion of the knee. There were no Café-au-lait spots or other signs of neurofibromatosis. Radiograph of the Knee revealed lucency in the distal end of the Right femur. Differential diagnoses considered were Fibrous cortical defects and Non-ossifying Fibromas. MRI of the Right knee revealed multiple well defined bubbly lytic lesion with sclerotic margin and eccentrically along the cortex in the distal femur. A similar lesion was seen in the proximal tibia. Later bone curettage was performed and histopathology examination revealed findings consistent with non-ossifying fibroma.Here we present a rare case of non-syndromic multiple non-ossifying fibromas.

Keywords: Type 1 neurofibromatosis, multiple, non-ossifying fibromas, non-syndromic, lytic, Café-au-lait spots, Fibrous cortical defects, sclerotic, Genu Valgum.

Copyright () 2020 The Author(s): This is an open-access article distributed under the terms of the Creative Commons Attribution 4.0 International License (CC BY-NC 4.0) which permits unrestricted use, distribution, and reproduction in any medium for non-commercial use provided the original author and source are credited.

\section{INTRODUCTION}

Syndromic Multifocal non-ossifying fibromas have been reported in patients with the JaffeCampanacci syndrome (multiple NOFs, café-au-lait spots, mental retardation, hypogonadism or cryptorchidism, ocular anomalies or cardiovascular malformations) [1-3] and in patients with Type 1 neurofibromatosis [4]. Evans and park reported a rare case of three members of a family with existence of multiple, symmetrical, non-ossifying fibromatosis without associated neurofibromatosis. These patients had upper and lower extremity involvement and no family history of neurofibromatosis [5]. Here we report a rare case of non-syndromic multiple non ossifying fibroma.

\section{ExPERIMENTAL SECTION}

A 23-year-old male complained of bowing deformity in the Right knee for 10 years. The deformity was insidious in onset, gradually progressive in nature, and made him sit with a wide base between the two feet. Initially, the base was non-progressive with minimal distance between the two feet but now the distance has increased to the length of a brick. There was no history of pain, trauma, or difficulty to perform routine activities. On examination, Genu Valgum of the right knee was diagnosed and the disappearance of the deformity was noted during flexion of the knee. There were no Café-au-lait spots or other signs of neurofibromatosis. There was no evidence of limb length discrepancy, wasting of quadriceps or calf muscles and hyperextension of knee.

Radiograph of knee revealed lucency in distal end of Right femur (fig. 1 and 2). Differential diagnosis considered were Fibrous cortical defect and Non ossifying Fibroma. MRI of the right knee in PD TSE sequence revealed multiple well defined bubbly lytic lesion with sclerotic margin and eccentrically along the cortex in distal femur, in the lateral condyle measuring 1.8 x $3 \mathrm{~cm}$ (fig.3), distal metaphysis measuring $2 \times 1.3 \mathrm{~cm}$ (fig. 3 ), and in the medial condyle measuring $2 \times 1.2 \mathrm{~cm}$ (fig.4). Similar lesion is seen in the proximal tibia measuring $1.7 \times 0.9 \mathrm{~cm}$ (fig. 4).

The lesions appear intermediate to low signal on T1WI (fig. 5 and 6) with a high signal on T2 TSE (fig. 7) and T1 STIR imaging (fig 8 and 9). No significant surrounding edema noted. No cortical break or periosteal reaction seen. 


\section{RESUlTS AND DISCUSSION}

Later bone curettage was performed and histopathology examination revealed findings of consistent with Non-ossifying fibroma.

Diagnosis of None ossifying Fibroma in the long bones is based upon the characteristic radiographic and clinical appearance, typically the Non ossifying Fibroma appears as an asymptomatic multiloculated lesion often identified incidentally during radiographic evaluation indicated for another reason [6-8]. While the majority of Non ossifying Fibroma are asymptomatic, those that are particularly large may cause chronic pain and/or pathologic fracture in the long bones $[9,10]$.When arising in a large, tubular bone, the Non ossifying Fibroma is always eccentric and ovoid and often results in thinning and expansion of the overlying cortex. There is usually no periosteal reaction [11] and no overt violation of the cortex [12].The lesions are often multilocular in appearance and the inner boundary of the lesion is demarcated by bony sclerosis $[13,14]$. While the definitive etiology of the Non ossifying Fibroma is unclear, it is considered to be a disturbance of growth or dystrophic calcification, rather than a tumour or neoplasm $[15,16]$.

Histologically, the Non ossifying Fibroma consists of spindle-celled fibrous tissue in a storiform pattern with a variable number of multinucleated giant cells, hemosiderin pigment within fibroblasts, and lipidladen histiocytes (xanthoma cells) $[17,18]$. In addition, occasional lymphocytes and endothelial-lined blood vessels are present [19-21]. The background stroma is composed of reticulin fibres [22, 23].

Radiographically all Non ossifying Fibroma lesions are categorized with respect to location, shape, border definition and presence of sclerotic changes according to Ritschl [24, 25] Stage A: Eccentric lesion in the cortex near the epiphyseal endplate, which is small, oval to slightly polycyclic in shape without a sclerotic border. Stage B: Lesions with variable distance from the epiphysis with polycyclic shape and thin but clearly sclerotic borders, thin cortex with occasionally protruding above the surface like the shape of an hourglass; no periosteal reaction. Stage C: Lesions with properties similar to stage $\mathrm{B}$ but with also exhibit increasing sclerosis, which typically start from the diaphyseal side. Stage D: Complete homogeneous sclerosis of the lesion (D1), disappearing lesion (D2) and disappearance of the lesion (D3).

The regressive phase is observed radiographically as a "fading out" of the lesion: trabecular bone growth appears to occur from the periphery inward until the bone is reconstituted to a normal state [26, 27]. Treatment of None ossifying Fibroma of the long bones, particularly in asymptomatic cases, is observation. These lesions are typically selflimiting and spontaneous resolution at skeletal maturity is usually seen, especially in the smaller lesions of the Fibrous cortical defect [28, 29]. This spontaneous regression, usually starting at the end of adolescence, has been observed to occur over periods of 29-52 months [6].

\section{CONCLUSION}

Here we present a rare case of non-syndromic multiple Non-ossifying fibromas.
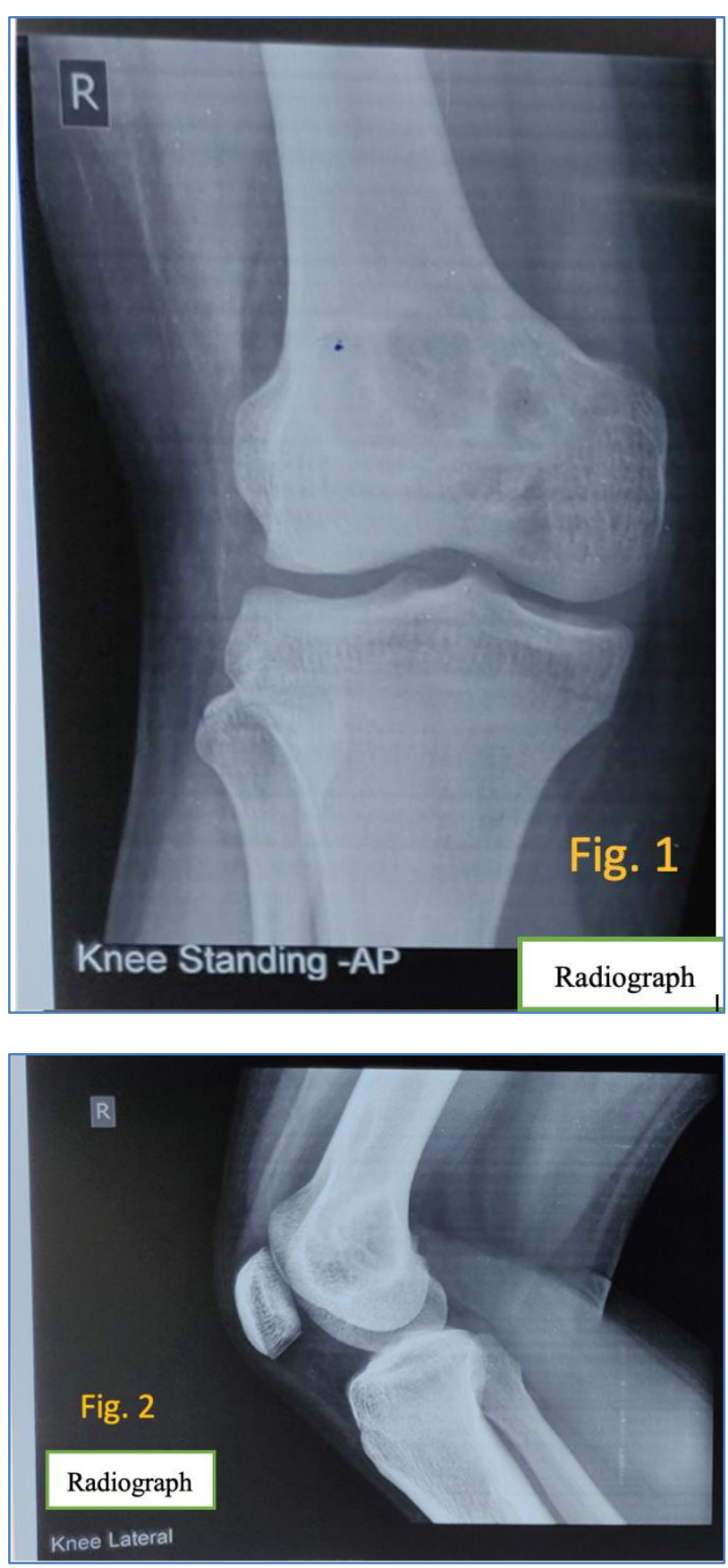

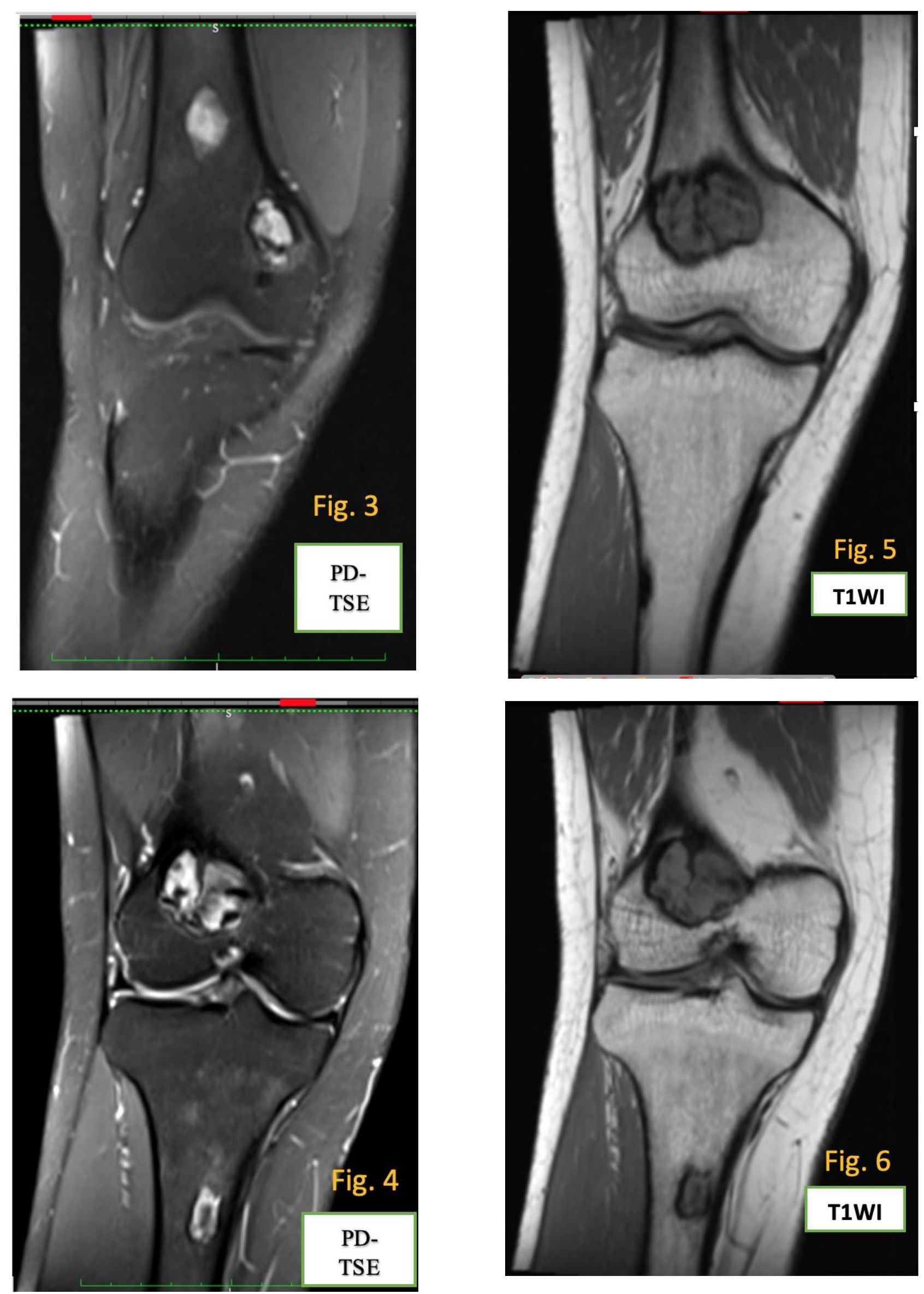

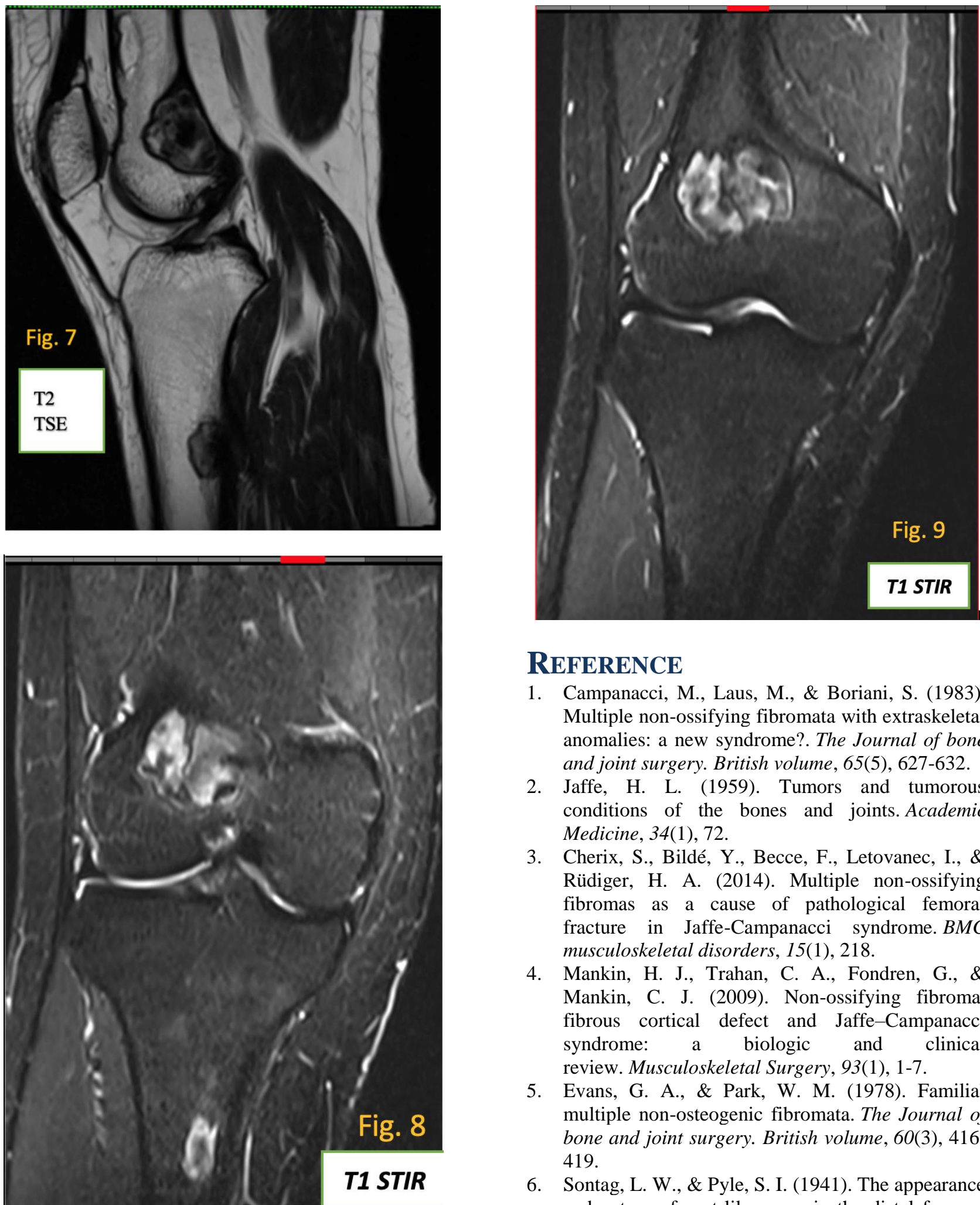

\section{REFERENCE}

1. Campanacci, M., Laus, M., \& Boriani, S. (1983). Multiple non-ossifying fibromata with extraskeletal anomalies: a new syndrome?. The Journal of bone and joint surgery. British volume, 65(5), 627-632.

2. Jaffe, H. L. (1959). Tumors and tumorous conditions of the bones and joints. Academic Medicine, 34(1), 72.

3. Cherix, S., Bildé, Y., Becce, F., Letovanec, I., \& Rüdiger, H. A. (2014). Multiple non-ossifying fibromas as a cause of pathological femoral fracture in Jaffe-Campanacci syndrome. BMC musculoskeletal disorders, 15(1), 218.

4. Mankin, H. J., Trahan, C. A., Fondren, G., \& Mankin, C. J. (2009). Non-ossifying fibroma, fibrous cortical defect and Jaffe-Campanacci syndrome: a biologic and clinical review. Musculoskeletal Surgery, 93(1), 1-7.

5. Evans, G. A., \& Park, W. M. (1978). Familial multiple non-osteogenic fibromata. The Journal of bone and joint surgery. British volume, 60(3), 416419.

6. Sontag, L. W., \& Pyle, S. I. (1941). The appearance and nature of cyst-like areas in the distal femoral metaphyses of children. Am J Roentgenol, 46(2), 185-8.

7. Shaffer, L. G., \& Tommerup, N. (Eds.). (2005). ISCN 2005: an international system for human cytogenetic nomenclature (2005): recommendations of the International Standing Committee on Human Cytogenetic Nomenclature. Karger Medical and Scientific Publishers. 
8. Brassesco, M. S., Valera, E. T., Engel, E. E., Nogueira-Barbosa, M. H., Becker, A. P., Scrideli, C. A., \& Tone, L. G. (2010). Clonal complex chromosome aberration in non-ossifying fibroma. Pediatric blood \& cancer, 54(5), 764-767.

9. Makek, M. (1980). Non-ossifying fibroma of the mandible. A common lesion with unusual location. Arch Orthop Trauma Surg, 96:225-227.

10. Hudson, J.W., Livesay, K.W., McCoy, J.M. (2003). (Condylar lesion. J Oral Maxillofac Surg, (61):824-826.

11. Dahlin, D. C. Fibroma (nonosteogenic fibroma of bone, metaphyseal fibrous defect), myxoma, cortical desmoid, fibromatosis, and "Xanthoma'. Bone tumors. general aspects and data on, 6, 122-36.

12. Blau, R. A., Zwick, D. L., \& Westphal, R. A. (1988). Multiple non-ossifying fibromas. A case report. JBJS, 70(2), 299-304.

13. Hudson, J.W., Livesay, K.W., McCoy, J.M. (2003). Condylar lesion. J Oral Maxillofac Surg, 61: 824826.

14. Aldred, M. J., Breckon, J. J. W., \& Holland, C. S. (1989). Non-osteogenic fibroma of the mandibular condyle. British Journal of Oral and Maxillofacial Surgery, 27(5), 412-416.

15. Hudson, J.W., Livesay, K.W., McCoy, J.M. (2003). Condylar lesion. J Oral Maxillofac Surg, 61:824826.

16. Aldred, M. J., Breckon, J. J. W., \& Holland, C. S. (1989). Non-osteogenic fibroma of the mandibular condyle. British Journal of Oral and Maxillofacial Surgery, 27(5), 412-416.

17. Schajowicz. F., Ackerman, L.V., Sissons, H.A. (1993). International histological classification of tumors (histological typing of bone tumors). Geneva: World Health Organization.

18. Mizukawa, N., Nishijima, Y., \& Nishijima, K. (1997). Metaphyseal fibrous defect (nonossifying fibroma) in the mandible: A case report. International journal of oral and maxillofacial surgery, 26(2), 129-130.
19. Quinn, J. H., Graves, L. R., \& Leonard, G. L. (1970). Unusual histiocytic lesion of the mandible: report of case. Journal of oral surgery (American Dental Association: 1965), 28(7), 528.

20. Elzay, R. P., Mills, S., \& Kay, S. (1984). Fibrous defect (nonossifying fibroma) of the mandible. Oral surgery, oral medicine, oral pathology, 58(4), 402-407.

21. Aldred, M. J., Breckon, J. J. W., \& Holland, C. S. (1989). Non-osteogenic fibroma of the mandibular condyle. British Journal of Oral and Maxillofacial Surgery, 27(5), 412-416.

22. Blau, R. A., Zwick, D. L., \& Westphal, R. A. (1988). Multiple non-ossifying fibromas. A case report. JBJS, 70(2), 299-304.

23. Huvos, A.G. (1979). Nonossifying Fibroma. In: Bone tumors: diagnosis, treatment, and prognosis. Philadelphia, PA: W. B. Saunders. 1979; 297-306.

24. Ritschl, P., Karnel, F., \& Hajek, P. (1988). Fibrous metaphyseal defects - determination of their origin and natural history using a radiomorphological study. Skeletal radiology, 17(1), 8-15.

25. Ritschl, P., Wiesauer, H., \& Krepler, P. (1995). Fibrous metaphyseal defects. Der Orthopade, 24(1), 44-49.

26. Mirra, J.M. (1989). Fibrohistiocytic tumors intramedullary origin. In: Mirra JM, editor. Bone tumors: clinical, radiologic, and pathologic correlation. Philadelphia: Lea \& Febiger, 692731.

27. Hatcher, C. H. (1945). The pathogenesis of localized fibrous lesions in the metaphyses of long bones. Annals of surgery, 122(6), 1016.

28. Jaffe, H. L., \& Lichtenstein, L. (1942). Nonosteogenic fibroma of bone. The American journal of pathology, 18(2), 205.

29. Bailey, J. S., Nikitakis, N. G., Lopes, M., \& Ord, R. A. (2001). Nonossifying fibroma of the mandible in a 6-year-old girl: a case report and review of the literature. Journal of oral and maxillofacial surgery, 59(7), 815-818. 